teeth. In the front of each large lateral plate is a narrow dorso-ventral sclerite carrying the jaws. These are two in number on each side. The anterior one (the mandible) is large, strong, toothed terminally, and provided on the inner side with a large, softer, movable lobe. The posterior jaw (the maxilla) is less chitinous than the other; it is flat and provided at its outer angle with several papilla-like processes.

\title{
GYNANDROMORPHISM IN A NEW SPECIES OF HILARA.*
}

BY AXEL LEONARD MELANDER, AUSTIN, TEXAS.

While collecting insects in Western Wyoming during September, I895, Dr. Wm. M. Wheeler chanced upon a very remarkable fly. This insect, Dilophus tibialis Loew, was taken among sweepings from the high grass along the borders of Hunter's Creek, at an altitude of about 8000 feet. The specimen was abnormal in the possession of an antennary appendage arising from the right fore coxa. Concerning this curious outgrowth Dr. Wheeler has already published a full account. $\dagger$

With the same sweepings in which the Dilophus was taken were numbers of an undescribed species of Hilara, and among these was another abnormal specimen. As cases of malformation are rare, and especially so among insects, possibly on account of the number of ecdyses which these animals undergo, the occurrence of another teratological

\footnotetext{
*(Contributions from the Zoological Laboratory of the University of Texas. No. 18).

$\dagger$ Archiv fuer Entwickelungsmechanik der Organismen. III. Band, 2 Heft, 1896.
}

fly in the same locality in which the Dilophus was taken is of some interest. The specimens collected were stored away until recently, when I undertook to study them in connection with the other species of Hilara.

Like most members of the genus Hilara, the new species exhibits striking sexual dimorphism, that is, apart from the peculiar hypopygial modifications, the first joint of the fore tarsi is greatly enlarged in the male, while of normal shape in the female. This character, which is well-nigh universal in the genus, is, like other secondary sexual characters, subject to considerable variation in form and size among the various species, and is therefore of taxonomic importance.

On sorting the Wyoming specimens with regard to the separation of the sexes, an individual was discorered which, so far as external characters ane concerned, is neither a male nor a female. This specimen has the abilominal styles of the female, while at the 
same time the front legs are modified as in the males. In other respects it is normal. Thus the front part of the body resembles the normal male, while the abdomen is exactly like that of the female. This case may be called "tandem " hermaphroditism. The figure illustrates the anomaly, together with the condition in a normal male, and a front leg of a normal female.

Although gyandromorphism is by no

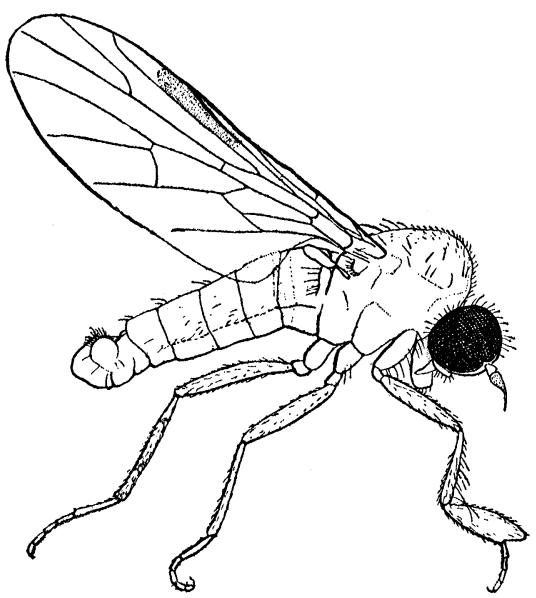

Hilara wheeleri n. sp. Male.

means unknown among insects, it nearly always occurs in the form of lateral hermaphroditism, as observed more commonly among Lepidoptera and less so among bees and ants. The occurrence of antero-posterior, or "tandem" hermaphroditism is rather rare, although quite as interesting as other cases of blending of sex. In this connection "Hahnenfedrigkeit" among female birds may be recalled.

As this species of Hilara has not been described, its diagnosis may properly be given in this connection.

Hilara Wheeleri sp. nov. Male and female. Length $3.5 \mathrm{~mm}$. Opaque true-black, covered with a very fine grey-glaucous coating. Head, thorax and abdomen with a few pale short hairs besides the dark bristles. Antennae black, short, third joint short, conical, its arista equal to itself. Palpi testaceous, with pale hairs: proboscis piceous, generally less than one-half the head-height. Thorax not vittate, its short hairs irregularly,

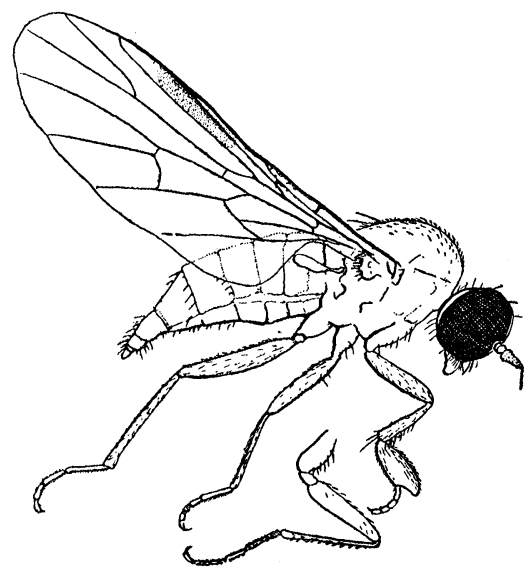

Hilara wheeleri n. sp. Gynandromorphic individual. The detached leg is the fore leg of a normal female. almost serially arranged: scutellum with four bristles, the inner pair long. Abdomen opaque black, most often compressed in the male and cylindrical or depressed in the female: no conspicuous bristles, the short sparse pubescence pale : hypopygium not of greater depth than the abdomen, sessile, rarely distinctly separated from the abdomen above, compressed, its lateral valves sub-glabrous, the dorsal filament thick, but almost always hidden. Legs fuscous to piceous. The males, as a rule, have the legs darker, but the fore tibiae are always fuscous. The pubescence is pale yellow: no conspicuous macrochaetae are present, though the 
hairs of the upper edge of the male fore tibiae are longer. The middle and hind coxae are black, the fore coxae more or less fuscous : tarsi black, the remainder of the legs variable in color from fuscous to piceous. The front metatarsi of the male enlarged, ovoid, the distal third of the inner side is excised for the reception of the remainder of the tarsus, which thus is not attached at the tip of the metatarsus. The front tibiae of the males are somewhat thickened. Wings cinereous-hyaline, stigmal spot faintly brown, neuration normal.

Seven males, twelve females and the gynandromorphic specimen.
Dubois (IX. 6, I895) and Little Wind River (IX. 2, I895) Wyoming.

This species seems to be allied to seriata, Loew, of the Eastern States, which also has ovate metatarsi in the males. As Dr. Loew does not mention the place of articulation of the second joint, it may be presumed that it is terminal to the metatarsus as in the other forms of the genus. Moreover, the middle tibiae of the male seriata are provided with rather long pubescence, a character not observable in Wheeleri.

\section{A NEW COCCID ON ROOTS OF RUBUS.}

\author{
BY T. D. A. COCKERELL.
}

Phenacoccus rubivorus, n. sp. $-9-\mathrm{Hem}-$ ispherical, with the form of a half-pea, distinctly segmented, pale pinkish, thinly covered with white mealy secretion; no cottony appendages. Boiled in liquor potassae, they stain the liquid amber yellow, and the skin becomes colorless. Anal ring with 6 hairs. Caudal tubercles very low and inconspicuous, with short bristles. Legs and antennae very pale brownish; claw with a small denticle on inner side; digitules slender, with small knobs. Antennae 9-jointed, formula approximately 92(35)6(47 I)8. The following measurements are in $\mu$ :-

Antennae segments ; (I.) 36 , (2.) $5 \mathrm{I}$, (3.) $48,(4) 39,.(5) 45$, (6.) 43 , (7.) 39 , (8.) 30, (9.) 69. Middle legs; femur + trochanter, 222 ; tibia, I74; tarsus, 90 ; claw, 27. Of course these measurements will vary, no two individuals being exactly alike.

The females studied contained very welldeveloped embryos. These showed small spines, round glands, and a small patch of spines on each lateral margin of each segment.

$H a b$ - Beulah, New Mexico, about 8,00o ft. alt., end of March, I9or, on roots of Rubus strigosus. Collected by Wilmatte P. Cockerell.

This interesting species does not have the superficial appearance of a Phenacoccus, though the antennae and legs are as in that genus. I suspect that when we know the male it will turn out to be congeneric with the little-known European Tetrura rubi described by Lichtenstein, concerning which see Entomologist, 1900, p. 86.

\section{A NEW SPECIES OF CHRYSOPA FROM TEXAS.*}

BY JESSE F. MCCLENDON.

Chrysopa bimaculata, sp. nov. Length to tip of wings $11.5 \mathrm{~mm}-13.5 \mathrm{~mm}$., alar expanse $2 \mathrm{I}-25 \mathrm{~mm}$.

Mouth short, antenna slightly shorter

* (Contributions from the Zoological Laboratory of the University of Texas, No. 19.) 

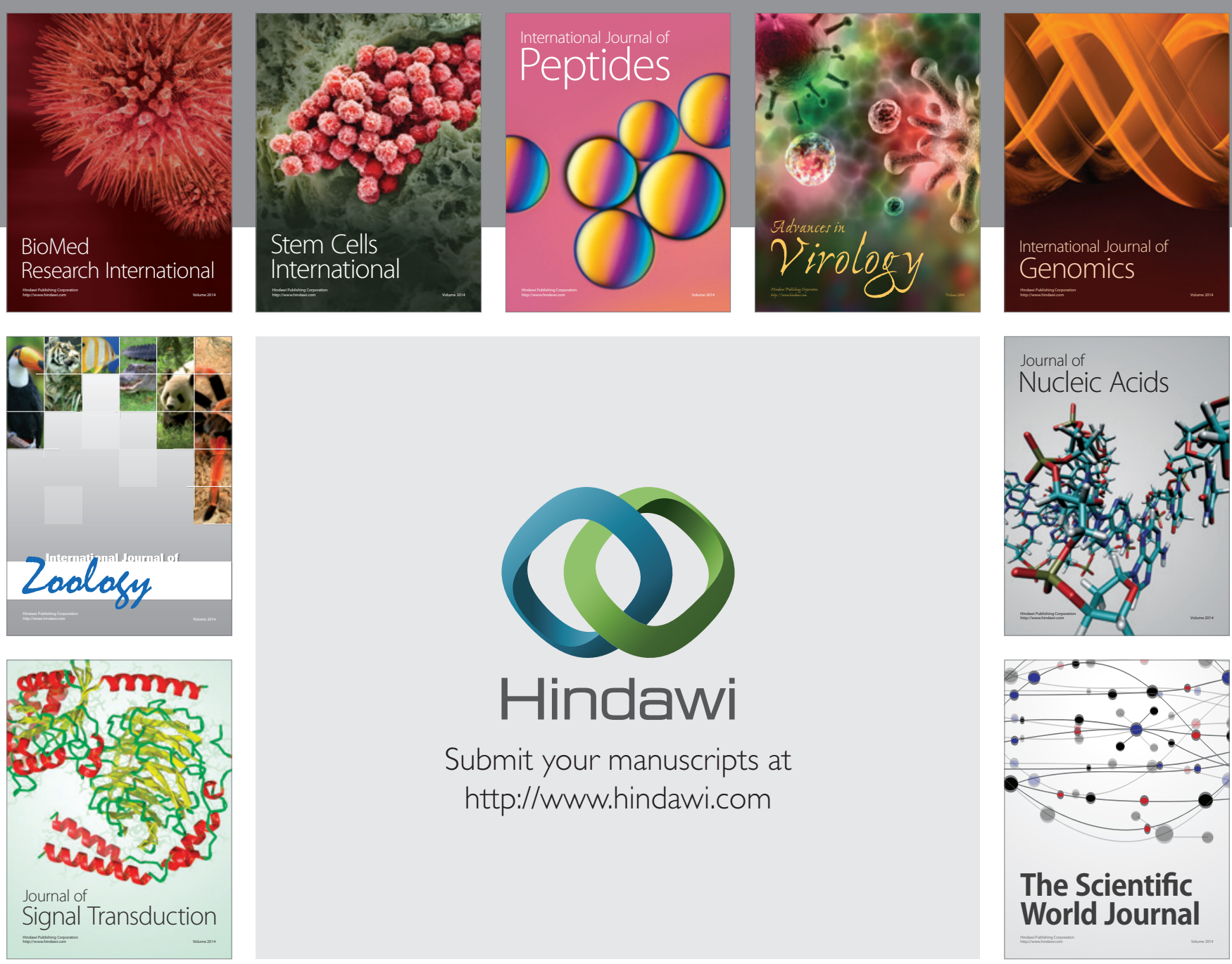

Submit your manuscripts at

http://www.hindawi.com
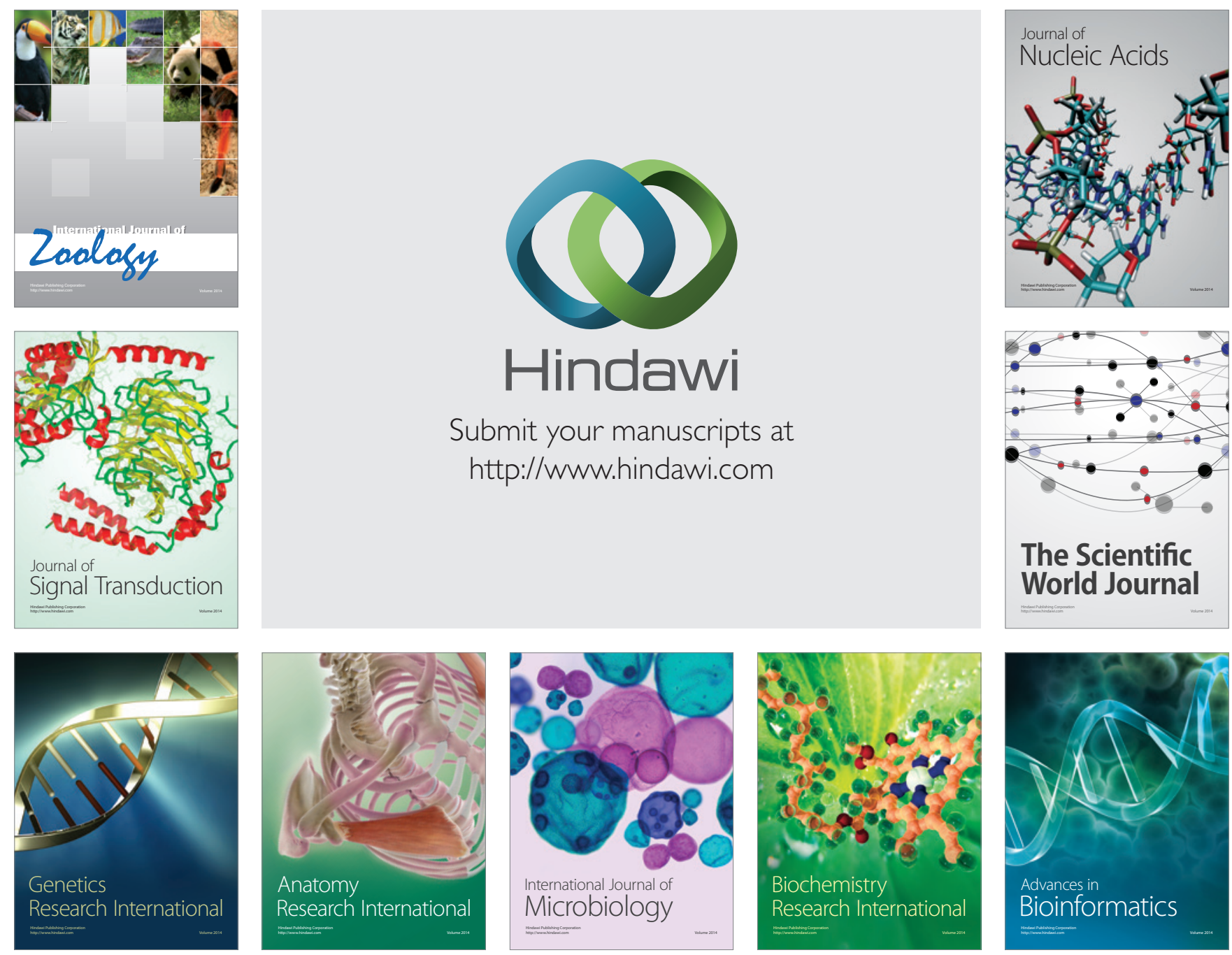

The Scientific World Journal
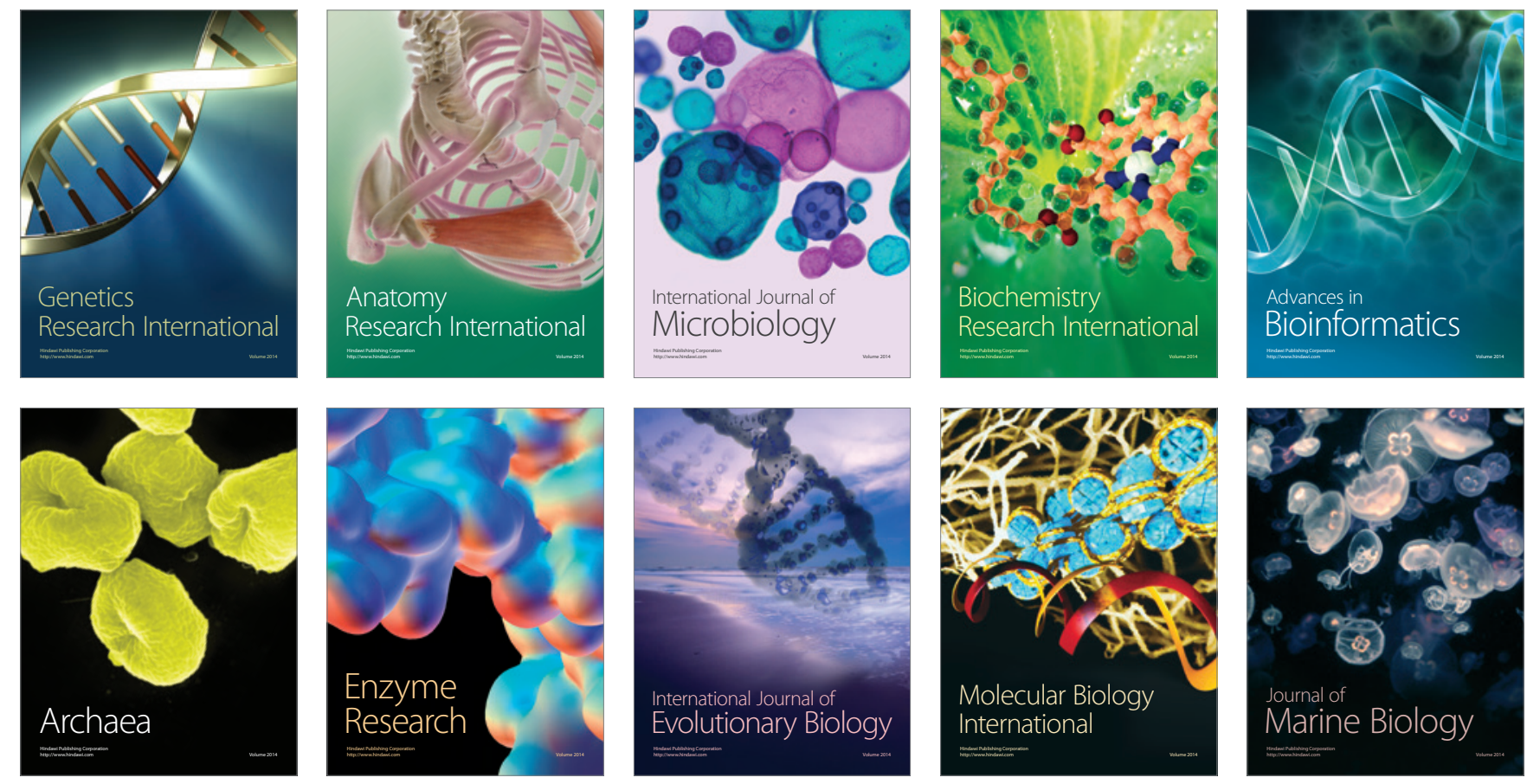